\title{
REDUÇÃO DE CUSTOS NA MINERAÇÃO ATRAVÉS DA GESTÃO DE ESTOQUES DE MINÉRIO
}

\author{
Walter Schmidt Felsch Junior ' \\ Leandro de Carvalho Zanini ${ }^{2}$ \\ Douglas Figueiredo de Souza ${ }^{2}$ \\ Douglas Emerich Gonçalves Oliveira ${ }^{2}$ \\ Alexandro Afonso Pinto ${ }^{3}$ \\ Pablo Rodrigo Vieira da Cunha ${ }^{2}$ \\ Éder Flávio de Araujo Costa ${ }^{2}$ \\ Guilherme Afonso Coutinho ${ }^{4}$
}

\section{Resumo}

O objetivo deste trabalho é mostrar a importância logística e financeira do controle dos estoques de minério em uma operação mineira. Foram analisados dois fluxos de movimentação de minério, sendo o primeiro considerado como fluxo ideal com movimentação de minério direto das frentes de lavra para a britagem. O segundo fluxo consiste na movimentação de minério para o estoque e depois para a britagem, caracterizando dupla movimentação. $O$ impacto no processo produtivo foi analisado, demonstrando como a gestão de estoques é fundamental na estratégia operacional de uma mineração. A metodologia utilizada inclui análises pluviométricas, tempo ocioso da frota de transporte, histórico de reposição e retomada de minério dos estoques e a definição de volume e qualidade necessários para a composição dos estoques. Como resultados, foram verificados a redução de movimentação de 5,2 milhões de toneladas de ROM (Run of Mine), gerando redução de consumo de óleo diesel de 980 mil litros e redução de custo operacional de R\$ 16,8 milhões nos anos de 2016 e 2017.

Palavras-chave: Estoques; Operação de mina; Gestão; Redução de custo.

\section{MINING COST REDUCTION THROUGH ORE STOCKPILES MANAGEMENT}

\begin{abstract}
The objective of this paper is to discuss the logistic and financial importance of the control of ROM stockpiles in a mining operation. Two flows of ore movement were analyzed, the first one was considered the ideal flow with ROM direct drive of the mining fronts to the crusher. The second flow consists of the movement of ore to the stockpile and then to the crusher, characterizing double movement. The impact on the production process was analyzed, demonstrating how the stockpile management is important in the operational strategy of a mining. The methodology used includes rainfall analysis, downtime of the transport fleet, history of replenishment and resumption of stockpiles, and the definition of volume and quality required for the composition of stockpiles. As a result, the reduction in the handling of 5.2 million tons of ROM was verified, generating a reduction in diesel oil consumption of 980 thousand liters and a reduction in operating costs of R\$16.8 million in the years 2016 and 2017.
\end{abstract}

Keywords: Stockpiles; Mine operation; Management; Cost reduction.

\section{INTRODUÇÃO}

O mercado mundial de bens minerais vive um momento de constante busca pelo aumento da produtividade e redução de custos em suas atividades. A rotina do trabalho no planejamento de lavra e nas operações de mina são fortemente atingidas através deste cenário.
Estatisticamente a composição dos custos das atividades unitárias em grande parte das minas que operam pelo método convencional de lavra por caminhões estão divididos em: $32 \%$ perfuração e desmonte, $16 \%$ carregamento e $52 \%$ com o transporte por caminhões [I-3]. Esse maior custo

'Universidade Federal de Ouro Preto - UFOP, Ouro Preto, MG, Brasil. E-mail: wsfelsch@hotmail.com

${ }^{2}$ Companhia Siderúrgica Nacional - CSN Mineração, Congonhas, MG, Brasil.

${ }^{3}$ Vale, Ouro Branco, MG, Brasil.

${ }^{4}$ Usinas Siderurgicas de Minas Gerais S.A - Usiminas, Belo Horizonte, MG, Brasil.

2176-1523 (c) 2020 Associação Brasileira de Metalurgia, Materiais e Mineração. Publicado pela ABM. Este é um artigo de acesso aberto distribuído sob os termos da licença Creative Commons CC BY-NC-ND (Attribution-NonCommercial-NoDerivs) - https:// creativecommons.org/licenses/by-nc-nd/4.0\%. 
do transporte se deve, em sua maioria, aos preços dos combustíveis fósseis e a aquisição de pneus para caminhões de grande porte. $\mathrm{Na}$ busca por maior produtividade, qualidade e redução de custos na indústria mineral, uma das principais questões é o transporte; no entanto, não deve ser a única a ser considerada. Estocagem e manuseio são atividades logísticas igualmente importantes para o alcance desses objetivos [4].

As empresas de mineração tendem a manter estoques de ROM para regular a alimentação da usina em momentos de interferência operacional, como desmontes, chuvas etc. Nos períodos de maior pluviometria, estes estoques são mantidos em níveis mais altos devido a um número maior de interrupções. $O$ uso de estoques eleva $\circ$ custo de produção, se tornando mais oneroso por necessitarem de uma segunda operação de carregamento e transporte para a sua retomada.

A função do estoque constitui na armazenagem de mercadorias e produtos com previsão de uso posterior. Seu objetivo principal é atender a demanda/procura, ou seja, disponibilidade de produtos ao cliente [5].

Dentre as muitas finalidades dos estoques podem-se citar: Estimular a economias na produção; Economia de escala nas compras e no transporte; Proteção contra aumentos de preço; Resguarda a organização contra incertezas na demanda/procura e no tempo de reabastecimento [6].

Os estoques são definidos como a acumulação armazenada de recursos materiais em um sistema de transformação. Apesar de custosos, eles garantem níveis de segurança em ambientes complexos e incertos [7].

A Figura I mostra o fluxo de destinação de material para o britador. O fluxo mais produtivo e de menor custo é caracterizado pelo carregamento na frente de lavra e basculamento direto na britagem. Quando os estoques são utilizados, o fluxo operacional se torna mais custoso, pois o mesmo material é carregado e transportado duas vezes.

O objetivo deste trabalho é mostrar a importância do controle dos estoques em uma empresa de grande porte do setor mineral. Será analisado o papel dos estoques no processo produtivo, bem como os impactos causados pelo excesso ou falta de material em sua composição, demonstrando como a administração do ROM é fundamental na estratégia da organização.

\section{DESENVOLVIMENTO}

O trabalho foi desenvolvido na mina Casa de Pedra, pertencente ao grupo CSN (Companhia Siderúrgica Nacional). Esta operação está localizada na cidade de Congonhas, MG. A empresa utiliza equipamentos de grande porte para a realização de movimentações de ROM, para produção de minério de ferro. Para o desenvolvimento do trabalho, foi criado um grupo multidisciplinar focado em melhoria contínua, com a participação de profissionais das áreas de planejamento de mina / controle de qualidade / despacho eletrônico, de maneira a buscar critérios e metodologias para o controle de estoques.

\section{I Materiais e Métodos}

A mina Casa de Pedra possui três estoques principais de minério, sendo eles diferenciados por tipos litológicos e teores granuloquímicos. A localização dos estoques também é um fator de grande importância no custo, pois a logística

\subsection{Fluxo Ideal de Transporte:}

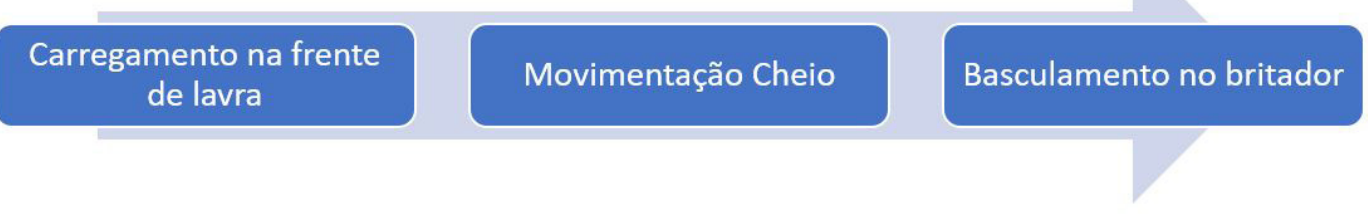

\subsection{Fluxo de Transporte com Estoques:}

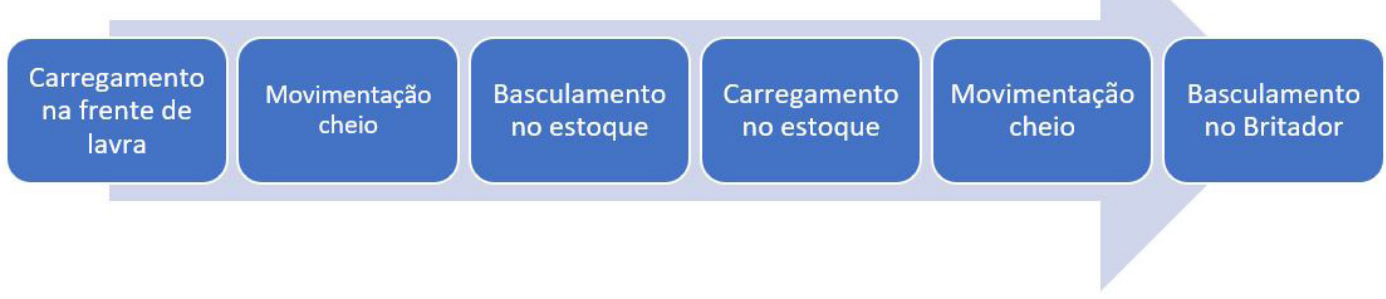

Figura I. Fluxos de movimentação entre as frentes de lavra e britagem. 
de composição e retomada influencia diretamente fatores operacionais como tempo de ciclo, produtividade horária de transporte $(\mathrm{t} / \mathrm{h})$ e consumo de combustível.

Na mina de Casa de Pedra os estoques de ROM localizados próximo ao britador e que serão alvo do gerenciamento proposto no trabalho são os seguintes:

- Estoque I: ROM brando de alto teor (acima de $58 \% @ \mathrm{Fe})$;

- Estoque II: ROM granulado de alto teor (acima de 60\%@Fe);

- Estoque 12: ROM brando de médio teor (entre 48\%-58\%@Fe);

Como premissas foram utilizados três parâmetros fundamentais para controle dos estoques:

I) Massa: Os estoques devem conter uma massa necessária para sua utilização de maneira a evitar paradas no sistema de britagem por falta de minério;

2) Qualidade: Os estoques devem ter a qualidade adequada para alimentação da britagem sem comprometer os teores químicos destinados aos clientes;

3) Permissibilidade: Os estoques só poderão ser utilizados quando as frentes de lavra da mina não estiverem acessíveis ou disponíveis.

Os pontos analisados foram divididos em 5 partes: Análise pluviométrica da região; histórico de paradas da frota de transporte; analise histórica de retomada dos estoques; definição das metas de massa e qualidade para cada estoque; e criação de rotinas de acompanhamento.

\section{I.I Pluviometria da região}

A pluviometria tem forte relação com a necessidade de retomada de minério dos estoques. Em períodos chuvosos a mina é mais susceptível a problemas associados a más condições de acessos para as frentes de lavra, sendo necessário a utilização do minério localizado nos estoques para alimentação da planta de beneficiamento. A massa do minério acumulada nos estoques é dimensionada para suprir a demanda em períodos de maior criticidade operacional.

A região de Congonhas possui dois períodos distintos, caracterizados como: período seco (Abril a Outubro) e período chuvoso (Novembro a Março).

\subsubsection{Histórico de paradas dos equipamentos de mina por motivos de origem climática}

Foi levantado um histórico de dados dos últimos 5 anos relacionado a baixa utilização da frota de transporte devido a alterações climáticas (chuvas e cerração). De acordo com os dados, o maior período identificado com baixa utilização de equipamentos devido a mal tempo foi de 9 dias consecutivos. Este número foi utilizado para limitar o valor de massa máxima na composição dos estoques.

\subsubsection{Histórico de utilização dos estoques}

Foi realizada uma análise histórica, em periodicidade mensal, da necessidade de utilização dos estoques na alimentação da britagem, relativo ao período de 2012 a 2015 . Outra análise realizada foi o valor médio de utilização dos estoques na alimentação da britagem de forma proporcional ao período climático (seco e chuvoso). A participação da massa de minério movimentada com destinação a britagem e origem nos estoques gira em torno de $20 \%$ da massa total, sendo que os outros $80 \%$ são referentes a movimentação com origem direta das frentes de lavra. Considerando somente a massa de minério com origem nos estoques com destinação para a britagem, o período chuvoso teve participação de $54,3 \%$, porém a participação dos estoques no período seco foi considerada elevada, com 45,7\%. A Figura 2 ilustra a participação mensal média de utilização dos estoques, relacionada com a massa total alimentada na britagem:

\section{I.4 Definição da massa e qualidade dos estoques}

A massa total calculada para compor os estoques da britagem foi de 880.000 toneladas, suficientes para 9 dias de alimentação, conforme definição informada no item "2.1.2".

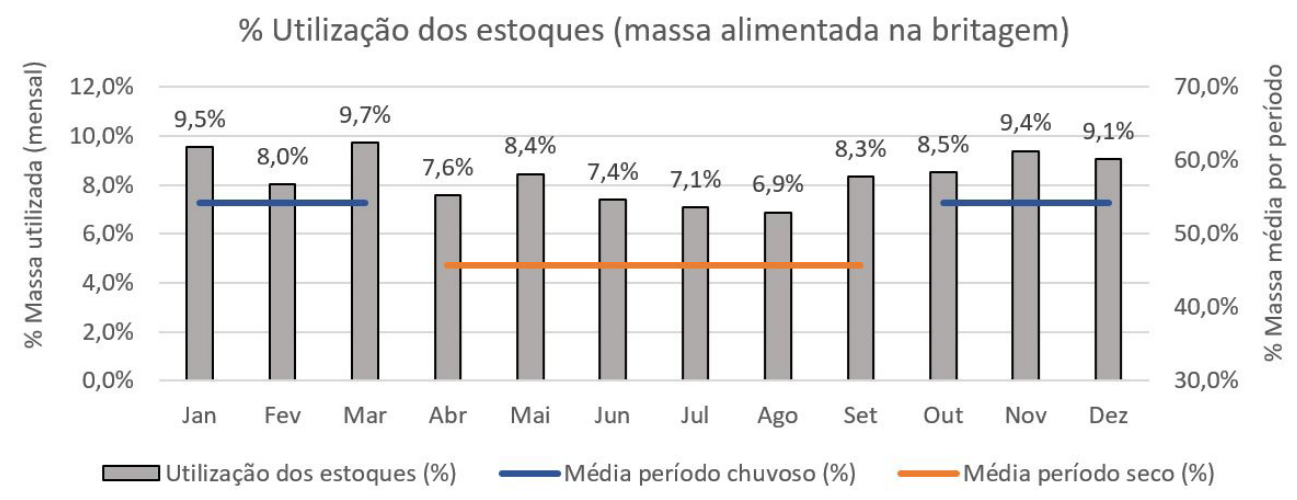

Figura 2. Histórico mensal de utilização dos estoques (\%) com destaque para a média por período (\%).

Tecnol. Metal. Mater. Miner., São Paulo, 
A distribuição de massa nos Estoques I, I I e I 2 foi calculada para que a retomada completa destes atenda às especificações vigentes para alimentação da britagem. O sinter feed, por ser o principal produto da usina de beneficiamento, utiliza como referência na formação destes estoques o teor de Ferro global de $62,9 \%$. As premissas para definição dos materiais que serão estocados são: teor de ferro, teor de contaminantes e granulometria do minério. Por definição operacional, o Estoque I recebe minério fino de alto teor, podendo ser Hematitas brandas e Itabiritos brandos ricos com teores acima de $58 \%$ de Ferro. O Estoque 12 recebe os itabiritos brandos silicosos, com teores abaixo de $58 \%$ de Ferro. O Estoque II recebe material granulado com teor acima de $60 \%$ de Ferro, como Hematitas e Itabiritos Compactos.

Na Tabela I, abaixo, é apresentado o teor médio e split de cada estoque de minério, calculado através de amostragens realizadas durante a sua formação:

\section{I.5 Rotinas de acompanhamento}

Foi incluído na rotina do plano de lavra semanal o controle de acompanhamento da formação dos estoques através de uma reunião específica para fornecimento de minério para as plantas de beneficiamento. Outro ponto fundamental foi a criação de uma metodologia para programação das pilhas de minério através de simuladores vinculados a ferramenta Solver (Microsoft Excel). A programação contempla toda a massa destinada a alimentação da britagem e busca minimizar a utilização dos estoques, priorizando as frentes de lavra como principais fornecedores de minério.

\section{RESULTADOS}

Foram verificados ganhos com a redução de massa movimentada no empilhamento e retomada dos estoques de ROM após a implementação do trabalho.

A Figura 3 mostra a evolução dos resultados, em periodicidade mensal nos anos de 2015 a 2017, dos valores de massa ( $\mathrm{t}$ ) retomada dos estoques de ROM, com destaque para a redução de massa movimentada no período de baixa precipitação em 2016 e 2017. Foi constatada uma redução de $55,8 \%$ no valor de massa retomada dos estoques para alimentação da britagem comparando os anos de 2015 e 2017 e redução de $33,5 \%$ na massa utilizada para recomposição dos estoques. Estes resultados geraram uma redução na movimentação de ROM na mina em 5,2 milhões de toneladas.

Após a implementação do trabalho, a massa de minério utilizada para alimentação da britagem oriunda dos estoques no período chuvoso aumentou de $54,3 \%$ para $79,6 \%$ da massa total relacionada a operação dos estoques. Já a utilização da massa de minério dos estoques no período seco, caiu de $45,7 \%$ para $20,4 \%$, mostrando a eficiência da metodologia criada, pois reduziu-se a massa movimentada para composição dos estoques no período seco. A Figura 4, abaixo, ilustra o resultado obtido comparando os anos de 2015 e 2017 :

Tabela I. Massa e qualidade dos estoques I, II e I2

\begin{tabular}{ccccccc}
\hline \multirow{2}{*}{ Est. } & $\begin{array}{c}\text { Capacidade } \\
\text { Máx. (kt) }\end{array}$ & $\begin{array}{c}\text { Massa } \\
\text { Necessária (kt) }\end{array}$ & \% & \multicolumn{3}{c}{ Sinter Feed } \\
\hline Est. I & 550 & 370 & 37 & 65,9 & SiO2 & Al2O3 \\
Est. II & 270 & 246 & 35 & 63,46 & 4,34 & 1,23 \\
Est. I2 & 370 & 264 & 31 & 56,9 & 15,74 & 0,80 \\
Global & $\mathbf{1 . 1 9 0}$ & $\mathbf{8 8 0}$ & $\mathbf{3 5}$ & $\mathbf{6 2 , 9}$ & $\mathbf{6 , 5 7}$ & $\mathbf{1 , 2 9}$ \\
\hline
\end{tabular}

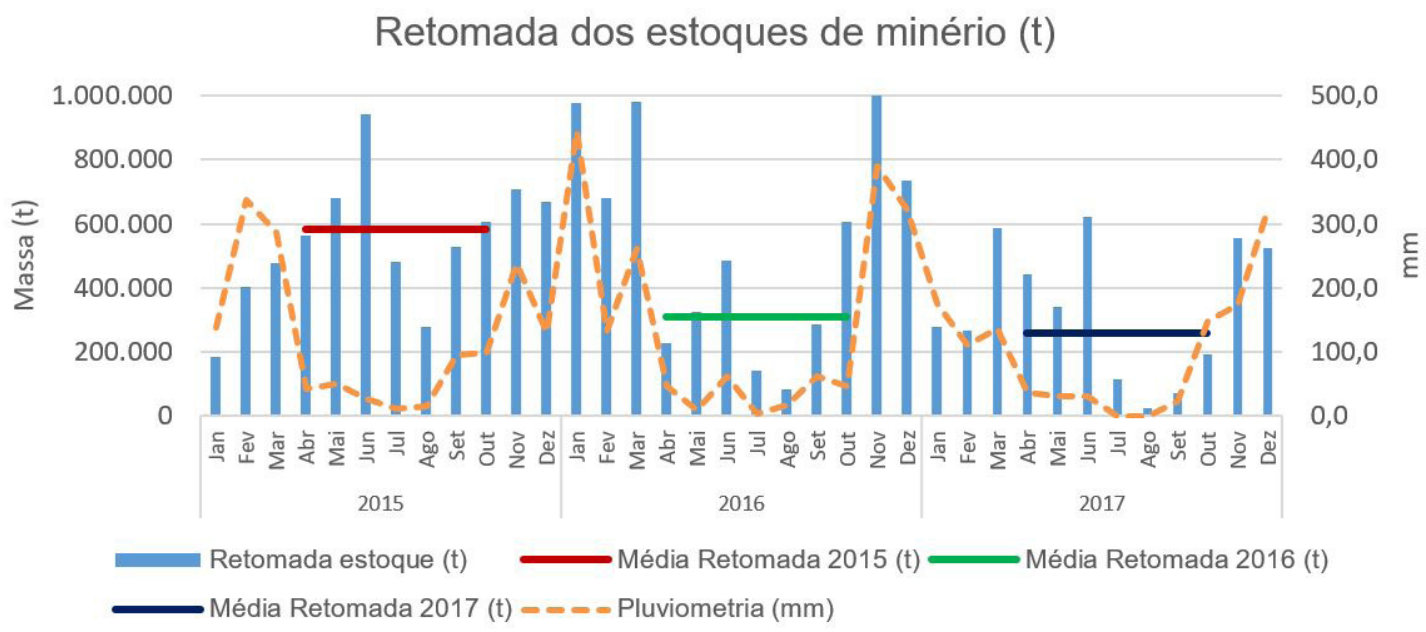

Figura 3. Análise mensal da massa retomada dos estoques (t). 


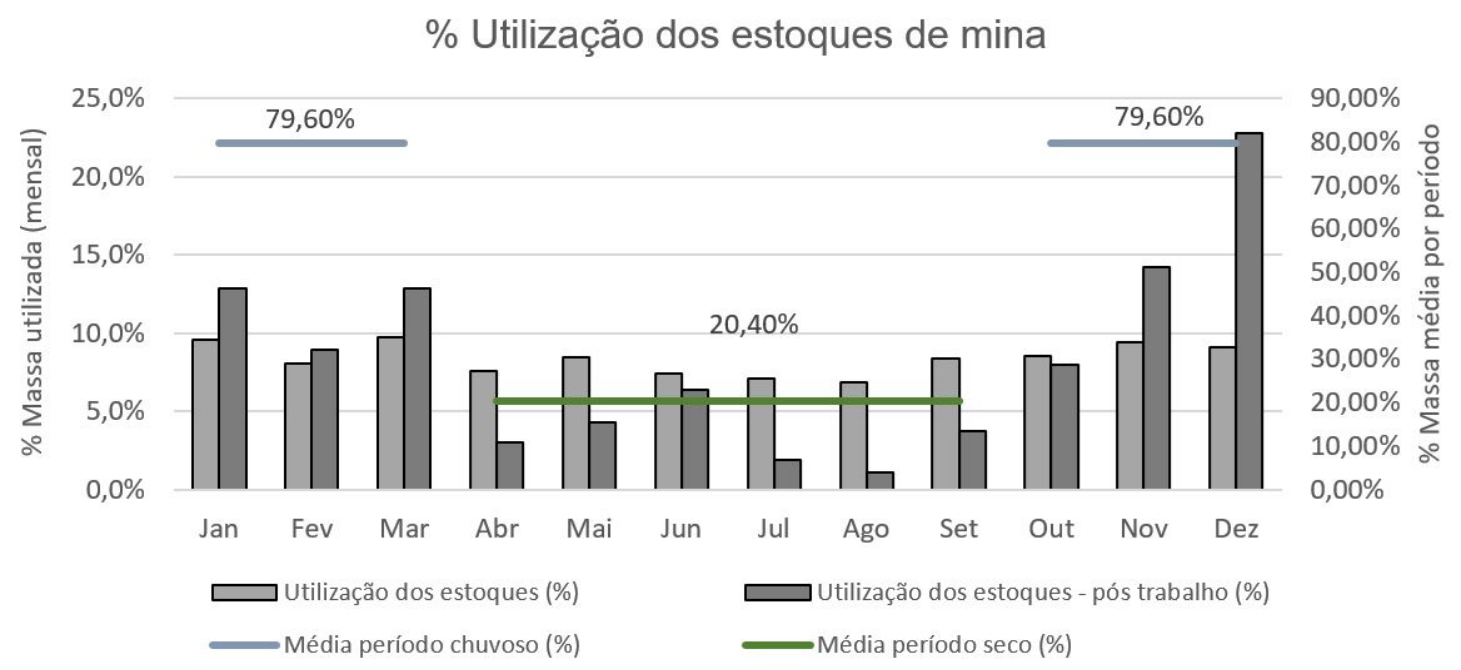

Figura 4. Comparativo mensal de utilização dos estoques (\%) na alimentação da britagem (20I5 e 20I7) com destaque para as médias dos períodos seco e chuvoso em 2017.

\section{I Ganhos Obtidos}

$\checkmark$ Redução na movimentação de 5,2 milhões de toneladas de ROM;

$\checkmark$ Redução do consumo de 980 mil litros de óleo diesel;

$\checkmark$ Redução do custo operacional em R\$16,8 milhões nos anos de 2016 e 2017.

\section{DISCUSSÂO}

O controle dos estoques de minério (ROM) aumentou a movimentação da mina no fluxo considerado ideal (origem nas frentes de lavra e destino britador) e reduziu consideravelmente a movimentação de material realizada com origem nos estoques, bem como sua recomposição. A redução de movimentação de minério para estocagem na mineração pode gerar várias alternativas de estudos para o planejamento das atividades de carregamento e transporte, como o redimensionamento da frota, que pode ser reduzida.

Outro ponto de grande importância do trabalho é a redução do consumo de óleo diesel da frota. Além de reduzir a emissão de gás carbono na atmosfera, gera importante redução de custos operacionais, já que o diesel é um dos insumos que mais impactam o OPEX em empreendimentos mineiros [8].

As decisões que envolvem estoques são de alto risco e impacto. Em determinados casos o excesso de estoques é usado para acomodar operações, gargalos ou a garantia de manter-se no mercado, em outros, com o avanço da tecnologia e da globalização do fornecimento, o estoque e a administração dos mesmos, assume papel crucial na estratégia competitiva da empresa [9].

As empresas fazem o uso de estoques para melhorar o fluxo entre oferta e procura, igualmente a fim de reduzirem seus custos totais. A estocagem torna-se, mais do que necessidade, uma conveniência econômica [10].

\section{CONCLUSÃO}

Os resultados alcançados confirmaram as premissas iniciais do trabalho: falta de controle na retomada e recomposição dos estoques de ROM aumenta o custo operacional da mina. Foi verificado que estas movimentações ocorriam por falta de controle efetivo dos estoques. $O$ controle aumentou a movimentação da mina no fluxo considerado ideal (origem nas frentes de lavra e destino britador).

A implantação da gestão e controle dos estoques de minério da mina Casa de Pedra foi realizada com sucesso. A massa e a qualidade dos estoques foram calculadas de acordo com análises históricas e se mostraram adequadas com a realidade da mina. A movimentação de material originada nos estoques com destino ao britador foi reduzida em $55,8 \%$, no período de 2015 a 2017 . Este trabalho proporcionou uma redução de $R \$ 16,8$ milhões no valor do custo operacional da unidade Casa de Pedra nos anos de 2016 e 2017.

\section{REFERÊNCIAS}

I Trueman E. In pit crushing: the application and benefits of track mounted crushing equipment. In: Goldfields Mining Expo. Proceedings of the National Seminar on New Trends in Cost Effective Iron Ore Mining; 200I; Noamundi, Bhar, Índia. Western Austrália: Goldfields Mining Expo; 200I. 27 p. 
Felsch Junior et al.

2 Mohutsiwai M, Musingwini C. Parametric estimation of capital costs for establishing a coal mine: South Africa case study. Journal of the South African Institute of Mining and Metallurgy. 20I5; I I5(8):20I5. http://dx.doi. org/I0.17I59/24II-97I7/20I5/VII5N8AI7.

3 Borges TC. (20।3). Análise dos custos operacionais de produção no dimensionamento de frotas de carregamento e transporte em mineração [dissertação]. Ouro Preto: Programa de Pós-graduação, Departamento de Engenharia de Minas, Escola de Minas, Universidade Federal de Ouro Preto.

4 Fortes FF, Pereira CA. Manuseio, estocagem e qualidade do minério de ferro. Tecnologica em Metalurgia, Materiais e Mineração. 2012;9(2): I I 7-122.

5 Ching HY. Gestão de estoques na cadeia de logística integrada. São Paulo: Atlas; 200 I.

6 Ballou RH. Logística empresarial. São Paulo: Atlas; 1993.

7 Dias MAP. Administração de materiais: princípios, conceitos e gestão. 6. ed. São Paulo: Atlas; 2010.

8 Soofastaei A. (2018). The application of artificial intelligence to reduce greenhouse gas emissions in the mining industry. In: Pacheco M, editor Green technologies to improve the environment on earth. London: IntechOpen. http://dx.doi.org/l 0.5772/intechopen.80868.

9 Slack N. Administração da produção. 2. ed. São Paulo: Atlas; 2008.

10 Ballou RH. Logística empresarial: transporte, administração de materiais e distribuição física. 5. ed. Porto Alegre: Bookman; 2006.

Recebido em: 19 Fev. 2019

Aceito em: 8 Nov. 2019 